University of Nebraska - Lincoln

DigitalCommons@University of Nebraska - Lincoln

\title{
Estimating daily gross primary production of maize based only on MODIS WDRVI and shortwave radiation data
}

\author{
Toshihiro Sakamoto \\ National Institute for Agro-Environmental Sciences, Tsukuba, Ibaraki, Japan; sakamt@affrc.go.jp \\ Anatoly Gitelson \\ University of Nebraska-Lincoln, agitelson2@unl.edu \\ Brian D. Wardlow \\ University of Nebraska-Lincoln, bwardlow2@unl.edu \\ Shashi Verma \\ University of Nebraska-Lincoln, sverma1@unl.edu \\ Andrew E. Suyker \\ University of Nebraska-Lincoln, asuyker1@unl.edu
}

Follow this and additional works at: https://digitalcommons.unl.edu/natrespapers

Part of the Natural Resources and Conservation Commons

Sakamoto, Toshihiro; Gitelson, Anatoly; Wardlow, Brian D.; Verma, Shashi; and Suyker, Andrew E., "Estimating daily gross primary production of maize based only on MODIS WDRVI and shortwave radiation data" (2011). Papers in Natural Resources. 316.

https://digitalcommons.unl.edu/natrespapers/316

This Article is brought to you for free and open access by the Natural Resources, School of at DigitalCommons@University of Nebraska - Lincoln. It has been accepted for inclusion in Papers in Natural Resources by an authorized administrator of DigitalCommons@University of Nebraska - Lincoln. 


\title{
Estimating daily gross primary production of maize based only on MODIS WDRVI and shortwave radiation data
}

\author{
Toshihiro Sakamoto, ${ }^{1,4}$ Anatoly A. Gitelson, ${ }^{2}$ Brian D. Wardlow, ${ }^{1}$ \\ Shashi B. Verma, ${ }^{3}$ and Andrew E. Suyker ${ }^{3}$ \\ 1. National Drought Mitigation Center, School of Natural Resources, University of Nebraska-Lincoln, Lincoln, NE, USA \\ 2. Center for Advanced Land Management Information Technologies, School of Natural Resources, University of Nebraska-Lincoln, Lin- \\ coln, NE, USA \\ 3. Great Plains Regional Center for Global Environmental Change, School of Natural Resources, University of Nebraska-Lincoln, \\ Lincoln, NE, USA \\ 4. Ecosystem Informatics Division, National Institute for Agro-Environmental Sciences, Tsukuba, Ibaraki, Japan; and JSPS postdoctoral fel- \\ low for research abroad. \\ Corresponding author — T. Sakamoto, 3-1-3 Kannondai Tsukuba-shi Ibaraki-ken, Japan, postal code 305-8604; email sakamt@affrc.go.jp

\begin{abstract}
Accurate assessment of temporal changes in gross primary production (GPP) is important for carbon budget assessments and evaluating the impact of climate change on crop productivity. The objective of this study was to devise a simple remote sensing-based GPP model to quantify daily GPP of maize. In the model, (1) daily shortwave radiation (SW), derived from the reanalysis data (North American Land Data Assimilation System; NLDAS-2) and (2) smoothed Wide Dynamic Range Vegetation Index (WDRVI) data, derived from Moderate Resolution Imaging Spectroradiometer (MODIS) 250-m observations were used as proxy variables of the incident photosynthetically active radiation (PAR) and the total canopy chlorophyll content, respectively. The model was calibrated and validated by using tower-based $\mathrm{CO}_{2}$ flux observations over an 8-year period (2001 to 2008) for one rainfed and two irrigated sites planted to maize as part of the Carbon Sequestration Program at the University of Nebraska-Lincoln. The results showed the temporal features of the product SW*WDRVI closely related to the temporal GPP variations in terms of both daily variations and seasonal patterns. The simple GPP model was able to predict the daily GPP values and accumulated GPP values of maize with high accuracy.
\end{abstract}

Keywords: Wide Dynamic Range Vegetation Index, Gross primary production, $\mathrm{CO}_{2}$-flux, Crop phenology

\section{Introduction}

Gross primary production (GPP) defined by carbon dioxide $\left(\mathrm{CO}_{2}\right)$ flux absorbed into plants through photosynthesis is a fundamental physical quantity for carbon balance computation between the atmosphere and terrestrial biosphere. Crops can assimilate larger amounts of carbon in their biomass during a growing season that is typically shorter than natural vegetation because of constant cultivar improvement under optimum management and growing conditions (i.e., cropping schedule set under given a climatic condition to maximize production through irrigation, fertilization and control of weed, pests, and diseases). Considering that allocation target of assimilated carbon is different between vegetative stages (mainly leaves, stems and roots) and reproductive stages (reproductive organs such as tassel and ears), the temporal feature of daily GPP value is supposed to play a key role for determining final crop yield from the viewpoint of crop phenology. Therefore, a remotesensing technique using time-series satellite images holds considerable promise to quantitatively evaluating the seasonal GPP variation among crops on a regional scale in terms of carbon assimilation and biomass.

Many existing GPP models based on remote sensing inputs follow a theoretical concept of the light use efficiency (LUE) model described by the following equation (Monteith, 1972):

$$
G P P=\varepsilon \times f P A R \times P A R
$$

where $P A R$ is the incident photosynthetically active radiation, $f P A R$ is the fraction of PAR absorbed by vegetation, and $\varepsilon$ is the LUE.

Recently, it was found that there is close consistent relationship between GPP and the product of total chlorophyll content ( $C h l_{\text {canopy }}$; defined as the product of LAI and leaf chlorophyll content) and PAR in crops (maize and soybean) with very different canopy structures and architectures (Gitelson et al., 2003, 2006):

$$
G P P \propto C h l_{\text {canopy }} \times P A R .
$$

Total canopy chlorophyll content is a main driver of absorbed PAR and it also related to nitrogen content and LUE (Baret et al., 2007; Houborg et al., 2011; Peng et al., 2011). Thus, it was suggested to use chlorophyll related vegetation indices to estimate remotely GPP in crops. This technique was tested using proximal sensing, $6 \mathrm{~m}$ above the top of canopy, in maize and soybean (Gitelson et al., 2006; Peng et al., 2011) and was successful in accurately estimating GPP using limited set of Landsat ETM+ data (Gitelson et al., 2008). 
The remote sensing-based GPP models used a wide variety of product data for explaining temporal variability of incident PAR (e.g. ground-observed incident PAR, reanalysis data including PAR, photosynthetic photon flux density, or shortwave radiation). The time step of model verification for assessing GPP estimates also varies from weekly to monthly depending on used explanatory variables (time resolution of composite VI or period for temporal averaging incident radiation data) and accumulation period of ground-observed GPP. Because it was often unclear how accurately these remote-sensing based GPP models could estimate daily and seasonal variation of GPP caused by daily fluctuation of incident PAR intensity, we (a) proposed a simple GPP model based on remotely sensed data, time-series MODIS 250-m Wide Dynamic Range Vegetation Index (WDRVI) and daily shortwave radiation (SW) reproduced in reanalysis data product (North American Land Data Assimilation System; NLDAS-2) and (b) investigated how effective the two proxy variables (WDRVI and SW) are for predicting daily GPP variations of maize. The simple GPP model was calibrated and validated using daily GPP data collected at three AmeriFlux sites in Nebraska over irrigated and rainfed maize over an eight-year period (2001 to 2008) and was found to accurately estimate GPP of maize.

\section{Review of remote sensing-based GPP models}

A wide variety of satellite sensors have been used for remote assessment of GPP including Landsat Enhanced Thematic Mapper (EMT+) (Chen et al., 2009; Gitelson et al., 2008), Moderate Resolution Imaging Spectroradiometer (MODIS) (Running et al., 2004; Schubert et al., 2010a, 2010b; Turner et al., 2006; Vina and Gitelson, 2005), Advanced Very High Resolution Radiometer (AVHRR) (Kitamoto et al., 2007), and SPOT VEGETATION (Xiao et al., 2004a). The vast majority of remote-sensing based GPP models used vegetation index (VI) data as a proxy variable for fPAR, which was assumed to have close relationship with vegetation community structure. Examples of VIs are the normalized difference vegetation index, NDVI (Rouse, 1974; Ruimy et al., 1994; Running et al., 2000; Schubert et al., 2010; Tucker, 1979), the enhanced vegetation index, EVI (Huete et al., 2002; Schubert et al., 2010; Xiao et al., 2005; Yan et al., 2009), the greenery ratio, GR (Harazono et al., 2009), the chlorophyll index, Chl index (Gitelson et al., 2006, 2008), and the MODIS leaf area index (LAI) product (Yuan et al., 2010).

Gamon et al. (1992) presented photochemical reflectance index (PRI) and found that it was correlated with the LUE of a sunflower canopy under nitrogen-stressed condition, but not under water-stressed condition. In this context, Nakaji et al. (2007) proposed a compound index, EVI/(PRI/PRI $\left.{ }_{\text {min }}\right)$ using the PRI and EVI for estimating the LUE of a mature Japanese larch (Larix kaempferi) forest. Inoue et al. (2008) used ground-based hyperspectral data to develop a new spectral index, NDSI $(710,410)$, for estimating the LUE of paddy rice. Yan et al. (2009) used a satellite-based vegetation photosynthesis model, VPM (Xiao et al., 2004 b), in which LUE was driven by temperature, water content, and leaf phenology derived from land surface water index, LSWI (Xiao et al., 2002), to evaluate seasonal dynamics of carbon flux in a wheat-maize double cropping system. Yuan et al. (2010) used the ratio of latent heat flux to net radiation instead of the Bowen ratio as a moisture constraint driving LUE in their eddy covariance LUE model (EC-LUE). Although a wide variety of GPP models based on LUE (Equation (1)) have been devised, there has not been a de-facto standard model for accurately estimating LUE. Several studies have also demonstrated a highly close relationship between satellite-derived VI and observed GPP values without considering seasonal variation of incident radiation data and LUE (Gitelson et al., 2008; Harris and Dash, 2010; Jahan and Gan, 2009; Nagai et al., 2010; Sims et al., 2006; Sjostrom et al., 2009; Wu et al., 2009; Xiao et al., 2004).
The aim of this study is to propose and test a simple GPP model using only time-series MODIS WDRVI and SW of reanalysis data for estimating daily GPP changes of maize.

\section{Materials and methods}

\subsection{Study sites and GPP-flux observation}

The study sites are located at the University of Nebraska Lincoln (UNL) Agricultural Research and Development Center near Mead, Nebraska, U.S.A.; http://csp.unl.edu/Public/sites.htm . The detail location and map of each site was shown in Sakamoto et al. (2010). At each site, $\mathrm{CO}_{2}$ flux of maize and soybean crops was measured by eddy covariance since 2001 as part of the Carbon Sequestration Program (CSP) at the UNL. Hourly GPP values were calculated. Suyker et al. (2004, 2005) and Verma et al. (2005) provide more details of the specific measurement techniques and calculations of GPP at these sites. These GPP data have often been used to validate the performance of the remote sensing-based GPP models for maize and soybean (Gitelson et al., 2003, 2006; Harris and Dash, 2010; Lokupitiya et al., 2009; Xiao et al., 2010; Yuan et al., 2010).

Study Sites $1\left(41^{\circ} 9^{\prime} 54.22^{\prime \prime} \mathrm{N}, 96^{\circ} 28^{\prime} .9^{\prime \prime} \mathrm{W}\right)$ and $2\left(41^{\circ} 9^{\prime} 53.5^{\prime \prime} \mathrm{N}\right.$, $\left.96^{\circ} 28^{\prime} 12.3^{\prime \prime} \mathrm{W}\right)$ are approximately 50 ha and are irrigated by a center-pivot system, while Site $3\left(4^{\circ} 10^{\prime} 46.8^{\prime \prime} \mathrm{N}, 96^{\circ} 26^{\prime} 22.7^{\prime \prime} \mathrm{W}\right)$ is rainfed and is approximately 60 ha in size. Site 1 is planted in maize each year, while Sites 2 and 3 are planted in a maize (odd years)-soybean (even years) rotation. In this study, we used 16-season*site of daily GPP data of maize observed during 20012008 (Verma et al., 2005).

The GPP values observed from DOY 160 to 270 , which define the maize's "core" growing season for these locations, were used to calibrate and validate the proposed GPP model. The 16-season*site GPP datasets were sorted and numbered in order of increasing season-total GPP regardless of the management method, and then were separated into two groups: 1) the data with odd number of the datasets (called calibration datasets) were used for establishing relationships between GPP and remotely sensed data (i.e., calibrating the model), and 2) the data with even number of the datasets (called validation datasets) were used for validation (i.e., for evaluating the prediction accuracy of calibrated GPP model (Table 1)).

\subsection{Shortwave radiation of NLDAS-2}

The SW estimates of the reanalysis dataset such as NASA's Data Assimilation Office (DAO), European Centre for MediumRange Weather Forecasts (ECMWF) and National Centers for Environmental Prediction/National Center for Atmospheric Research (NCEP/NCAR) are often used for global-scale GPP/NPP modeling (Pinker et al., 2010; Zhao et al., 2006). MODIS GPP product (MOD17) uses incident SW of DAO with other daily surface meteorological data such as air temperature, surface pressure and specific humidity in addition to ancillary MODIS products of land cover (MOD12), FPAR and LAI (MOD15) (Running et al., 1999; Zhao et al., 2005). In theory, it is not adequate to assign the SW to the GPP model, because the broad wavelength range of SW $(0.3-4.0 \mu \mathrm{m})$ includes the specific bands of water vapor absorption and relatively narrower range of PAR (0.4-0.7 $\mu \mathrm{m})$. There is another reanalysis dataset called Modern Era Retrospective-Analysis for Research and Applications (MERRA) that enables us to evaluate spatio-temporal changes in PAR on a global scale (Yuan et al., 2010), however the spatial resolution of these data is too low $\left(1 / 2 \times 2 / 3^{\circ}\right.$; ca. $56 \times 74 \mathrm{~km}$ at Equator $)$ in evaluating spatio-temporal changes in GPP of maize on field, county or state scale.

This study also used the SW data of the reanalysis dataset (NLDAS-2) as proxy variable for incident PAR. We took advantage of higher spatial resolution of the daily reanalysis data called NLDAS-2 (1/8 ; ca. $14 \mathrm{~km}$ at Equator). The footprint of 
Table 1. Calibration and validation of the models using SW*WDRVI as an explanatory variable for estimating daily GPP on different objective periods. Coefficient of variation (CV), root mean square error (RMSE), determination coefficient $\left(\mathrm{R}^{2}\right)$ and mean normalized bias (MNB) are given for each GPP model. The calibration dataset was the same as shown in Figure 3.

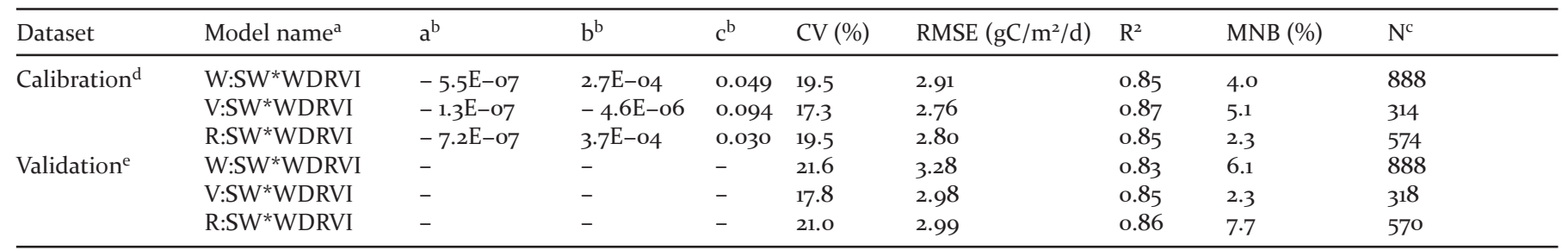

a. Objective periods; W means whole season from DOY 160 to 270, V means vegetative stages from DOY 16o to the estimated R1 stage, and R means reproductive stages from the estimated R1 stage to DOY 270.

b. a, b, c: coefficients of approximate equation $\left(y=a x^{3}+b x^{2}+c x\right)$.

c. N: number of samples (days) used for calibration and validation.

d. Data used for calibration (year, site no.) are 2001_S3, 2003_S2, 2003_S3, 2004_S1, 2005_S2, 2005_S3, 2007_S2 and 2008 _S1.

e. Data used for validation are 2001_S1, 2001_S2, 2002_S1, 2003_S1, 2005_S1, 2006_S1, 2007_S1 and 2007_S3.

one SW pixel (spatial resolution; ca. 11-km at the sites) covers all three sites. NLDAS-2 land-surface forcing files are derived from the analysis fields of the NCEP North American Regional Reanalysis (Fang, 2009).

According to assessment of uncertainty about the reanalysis SW itself (daily mean surface downward SW flux of NLDAS-2) by comparing with ground-observed incoming SW from 2001 to 2008 (all available days, $\mathrm{N}=2777$ ), the NLDAS-2 estimates of SW had determination coefficient $\left(\mathrm{R}^{2}\right)$ of 0.75 , root mean square error (RMSE) of $42.6 \mathrm{~W} / \mathrm{m}^{2}$, coefficient of variation (CV) of $23.9 \%$ and mean normalized bias (MNB) of $16.6 \%$.

As for uncertainty about the use of the reanalysis SW as a proxy of incident PAR, the reanalysis SW estimates (NLDAS-2) showed strong linear relationship $\left(\mathrm{R}^{2}=0.80\right)$ with ground-observed daily incident PAR on the basis of a randomly-selected $60 \%$ data $(\mathrm{N}=1666)$ of entire observation period from 2001 to 2008 (Figure $1 \mathrm{~A}$ ). The rest of randomly-selected $40 \%$ data $(\mathrm{N}=1111)$ were used to estimate uncertainty in PAR prediction using the reanalysis SW estimates (NLADS-2). CV of predicted PAR values was $23.6 \%$ (Figure $1 \mathrm{~B}$ ). Thus, it seemed reasonable to substitute daily-mean SW values for actual PAR observations to help detect the short-term variations of incident light intensity.

\subsection{MODIS WDRVI}

This study used an 8-day time-series of $250 \mathrm{~m}$ and $500 \mathrm{~m} \mathrm{MO-}$ DIS surface reflectance data (MODogQ 1 and MODogAı, Collection 5, tile: hiovo4), acquired from 2001 to 2008 . The $250 \mathrm{~m}$ red (Band 1) and near infrared (NIR, Band 2) reflectance data from the MODogQ1 were used for the WDRVI calculations. The $500 \mathrm{~m}$ blue (Band 3) and the observation-date data from the MODogA 1 were resampled from $500 \mathrm{~m}$ to $250 \mathrm{~m}$ resolution using the nearestneighbor method. The blue band and the observation-date data were used in wavelet-based filter for simply detecting cloud coverage and time interpolation, respectively. The layer-based resampling procedure was intended to simplify the program codes of image analysis for preventing wrong choice of target pixels in the preprocessing scheme. Then, the three MODIS-pixel locations were near central location of each experimental field as shown in a previous study (Sakamoto et al., 2010), which proposed a new crop phenology detection method for detecting maize and soybean phenology with time-series MODIS data.

WDRVI is calculated by the following equation (Gitelson, 2004):

$$
W D R V I=\left(\alpha \times \rho_{\mathrm{NIR}}-\rho_{\text {red }}\right) /\left(\alpha \times \rho_{\mathrm{NIR}}+\rho_{\text {red }}\right)
$$

where $\rho_{\text {NIR }}$ and $\rho_{\text {red }}$ are the $250 \mathrm{~m}$ MODIS surface reflectance values in the NIR band $(841-875 \mathrm{~nm})$ and the red band (621$670 \mathrm{~nm}$ ), respectively. The weighting coefficient of $\alpha$ is $\mathbf{0 . 2}$. WDRVI has been found to be linearly related with the green leaf area index (GLAI) of maize, soybean, and wheat (Gitelson, 2004). The utility of MODIS-based $250 \mathrm{~m}$ WDRVI data with $\alpha=0.2$ is to accurately estimate GLAI of maize and soybean (Gitelson et al., 2007). While the dynamic range of WDRVI against the GLAI and vegetative fraction of maize is wider than that of NDVI due to the weighting coefficient ( $\alpha$ in Equation (3), Gitelson, 2004), the WDRVI extends into the negative value range during early vegetative stages unlike NDVI and EVI (Gitelson et al., 2008; Peng et al., 2011). Considering the linear relationship between MODIS WDRVI and green LAI, MODIS WDRVI has the advantage of making it easy to interpret seasonal variation of this bio-physical parameter of maize and its contribution to daily GPP estimates.
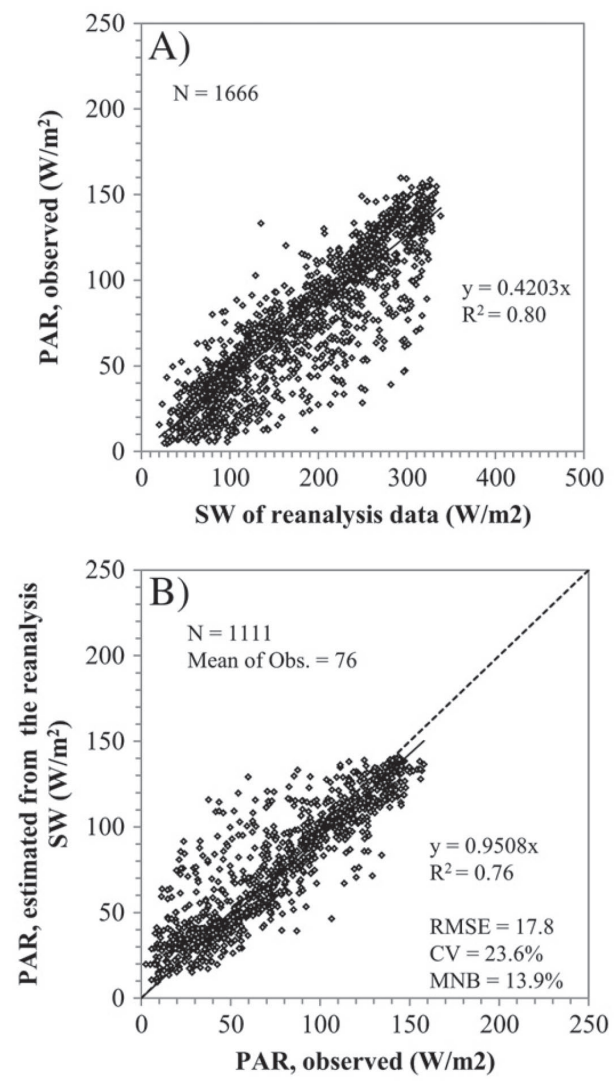

Figure 1. Comparison between the shortwave radiation (SW) from NLDAS-2 and the daily incident PAR (field-based observation) (A) using randomly-selected $60 \%$ data of entire observation period from 2001 to 2008 and (B) validation of uncertainty when applying the SWPAR relationship to estimate daily incident PAR using randomly-selected $40 \%$ data. 

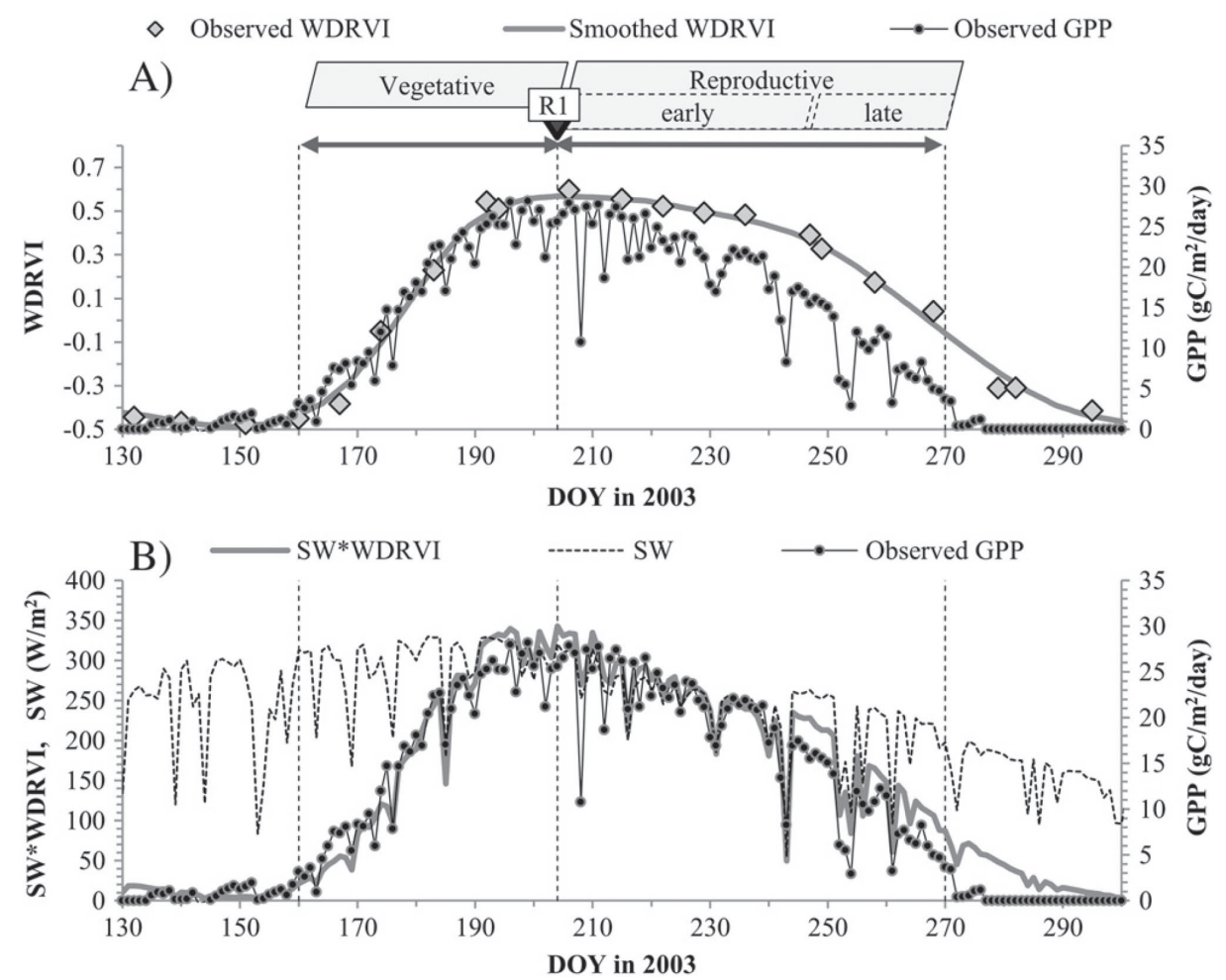

Figure 2. Temporal change in GPP and (A) the smoothed WDRVI, (B) the shortwave radiation (SW), product of SW and WDRVI: $\mathrm{SW}^{*}(\mathrm{WDRVI}+0.5)$ for maize grown at Site 2 in 2003.

\subsection{Smoothed WDRVI profile based on wavelet-based filter}

The 8-day composite MODIS surface reflectance (MODog product) is atmospherically corrected to reduce the effects of gaseous absorption and aerosol scattering (Vermote et al., 2002). An 8-day CV-MVC technique is also applied to avoid low quality observation values caused by poor observation conditions resulting from cloud cover and extreme large off-nadir observation angles. Even though the surface reflectance used to calculate the WDRVI went through these corrections, the observed WDRVI time-series is subject to include various residual noise components resulting in an erratic time series behavior of many sharp WDRVI value declines, because of the moderate spatial resolution $(250 \mathrm{~m})$ and wide view angle $\left( \pm 55^{\circ}\right)$ of MODIS. The irregular temporal features in the WDRVI time series data are caused by persistent and residual, sub-pixel cloud cover, bi-directional reflectance distribution function (BRDF) effects, and mixedpixel effects (i.e., multiple land cover type contained with the pixel's geographic footprint). Therefore, we applied the wavelet-based filter for filtering out the high-frequency noise components to produce daily interpolated and smoothed WDRVI profile from unequally-spaced observations of MODIS 8-day composite product. Figure 2A shows the observed 8-day WDRVI time-series data (diamond labels) and the smoothed WDRVI profile (solid gray line) in 2003 at Site 2.

The brief explanation of the procedures for smoothing and temporal interpolation of MODIS WDRVI is as follow. First, the potential cloud-covered pixels were detected by blue reflectance (greater than 0.2, Thenkabail et al., 2005; Xiao et al., 2006) in the preprocessing scheme for wavelet-based filter. Second, available WDRVI observations were linearly interpolated and resampled at equally spaced 5-day intervals in reference to the observation-date data recorded in MODogAs product. The reason why the input time-series WDRVI data were preliminary interpolated at 5-day intervals instead of daily intervals was that the smoothing procedure had been designed to save computation time and capacity of hard disk space for future application to re- gional-scale data. Third, a wavelet-based filter using a specific mother wavelet (coiflet, order $=4$ ) was applied to the prepared time-series WDRVI data for reducing the components with a frequency higher than a scale of 4 in the 5-day interval input array $(<20$ days $=4 \times 5)$ through wavelet and inverse transformations. Finally, the missing values between 5 -day intervals in the smoothed WDRVI output were linearly interpolated to provide daily smoothed WDRVI data. More details of the wavelet-based filter are provided by Sakamoto et al. (2005, 2010).

\subsection{Division of growing period into vegetative and reproductive stages}

As mentioned earlier, we used the GPP values observed during the growing season period, defined day of year (DOY) from 160 to 270; these GPP values were used for model calibration and validation. This specific date range was selected to avoid observations from non-growing season dates before planting and after harvesting. Considering the maize silking stage ( $\left.\mathrm{R}_{1}\right)$ is an appropriate indicator of the transition from the vegetative to reproductive stage, the new crop phenology detection method called Two-Step Filtering (TSF) approach was used to estimate the date of silking stages ( $\left.\mathrm{R}_{1}\right)$ of maize from the same temporal WDRVI profile (Sakamoto et al., 2010, 2011). The primary characteristic of the TSF method is a unique concept named "shape model fitting", which enables us to estimate four phenological stages of maize from $250 \mathrm{~m}$ MODIS WDRVI time-series data without using different VI metrics (e.g. fixed threshold value, seasonal midpoint, maximum point, or inflection point). The RMSE of silking stage ( $\left.R_{1}\right)$ estimation by this technique was 2.4 days. The period from DOY 160 to the estimated Ri stage was defined as vegetative stage while the period from the estimated Ri stage to DOY 270 was defined as reproductive stage (Figure 2). Moreover, according to the temporal features of time-series WDRVI data, the reproductive stage can be roughly segmented into the early reproductive and late productive stages before and after inflection point of decline WDRVI pattern (Figure 2A). 

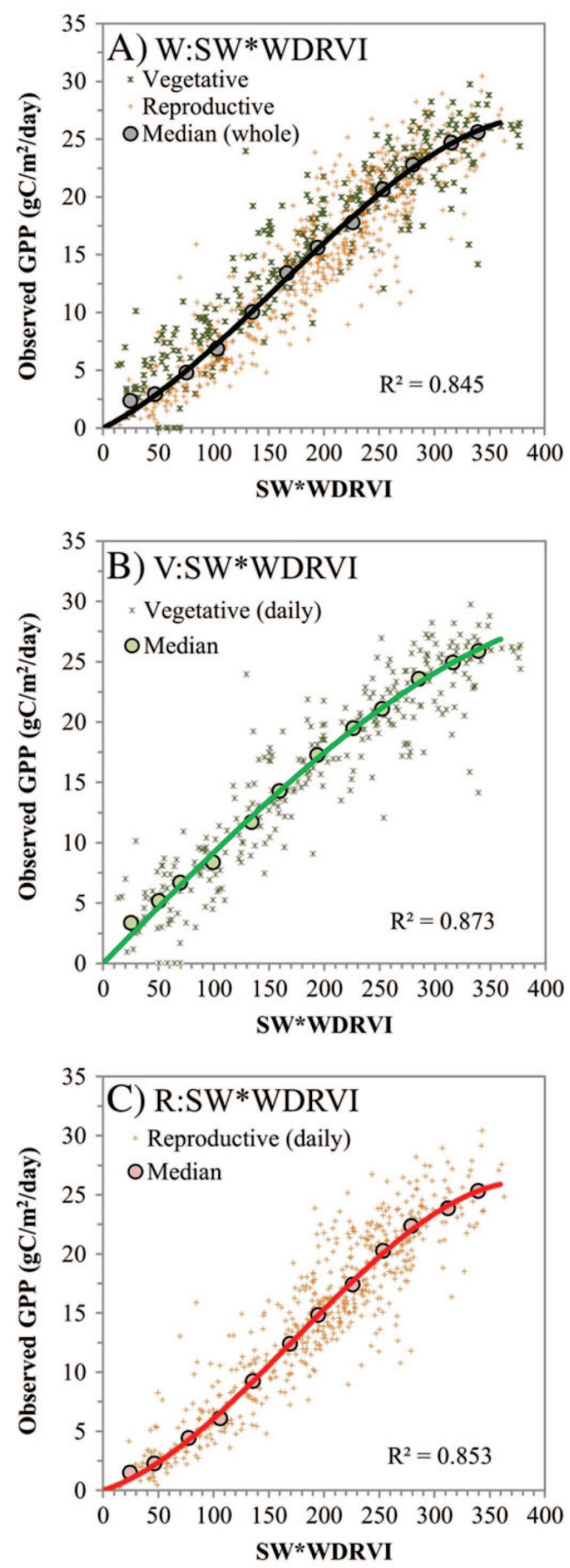

Figure 3. Scatter plots of observed GPP vs. SW*WDRVI in the calibration datasets. The approximation expressions were calibrated over different periods: (A) whole season $\mathrm{W}: \mathrm{SW}^{*} \mathrm{WDRVI},(\mathrm{B})$ vegetative stages $\mathrm{V}: S W^{*} \mathrm{WDRVI}$, and $(\mathrm{C})$ reproductive stages R:SW*WDRVI. The data shown here was the same as calibration dataset in Table 1.

\section{Results and discussion}

\subsection{Seasonality of GPP and WDRVI}

The maize WDRVI rapidly increases in a sigmoid fashion during the vegetative stage (Figure $2 \mathrm{~A}$ ). This sigmoid geometry was coincident with the seasonal pattern of the GPP, green LAI, and canopy chlorophyll content during the same period. The observed GPP values peaked near the Ri stage. After that, the WDRVI decreased slightly during the early reproductive stages (DOY: 200250). Then, the maize WDRVI rapidly decreased during the late reproductive stage after DOY 250, but the slope of this decreasing
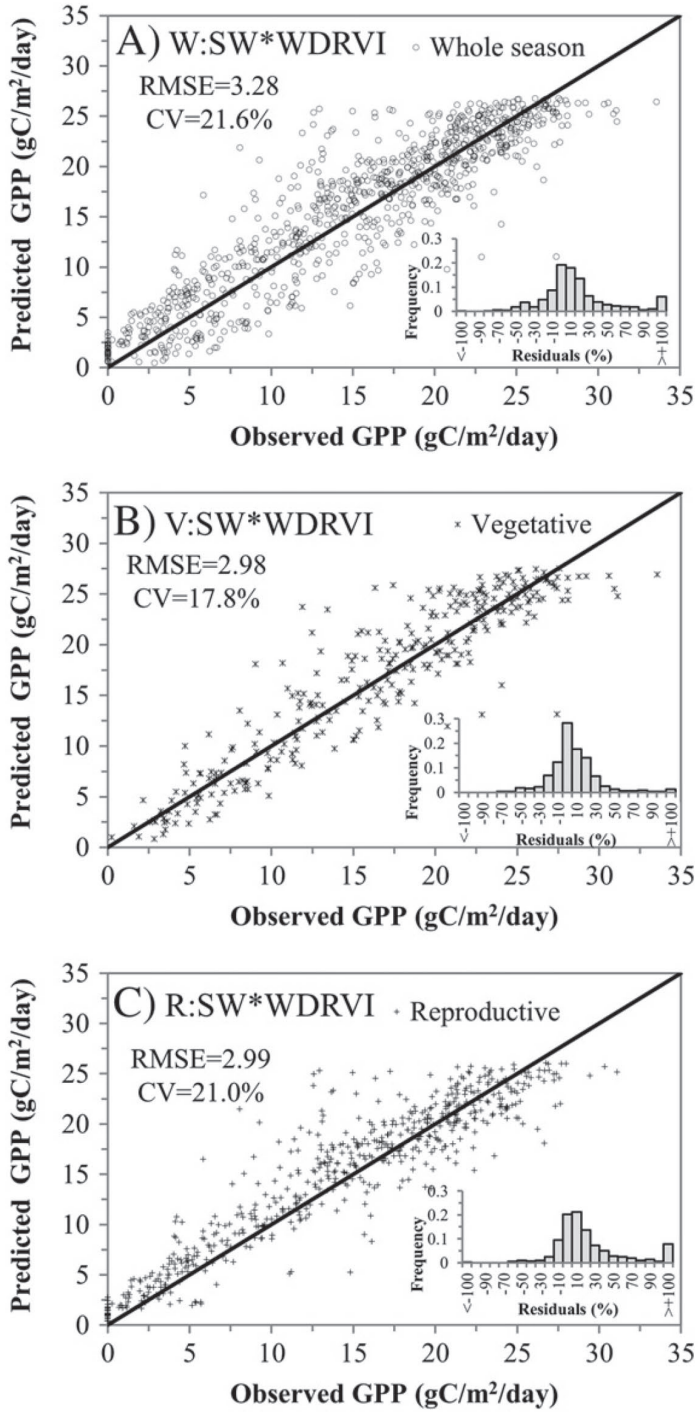

Figure 4. Validation of calibrated models when applying GPP models based on SW*WDRVI to the validation dataset. The applied GPP models were: (A) W:SW*WDRVI for whole-growing season, (B) $\mathrm{V}: \mathrm{SW}^{*} \mathrm{WDRVI}$ for vegetative stages and (C) R:SW*WDRVI for reproductive stages. Insets show the frequency distribution (expressed as a percent) of the residuals from the 1 by 1 line.

trend was less than that of the increasing trend observed during the vegetative stage earlier in the growing season.

While WDRVI follows GPP very closely in vegetative stage, there is a wide gap between WDRVI and GPP in reproductive stage. The reason for this discrepancy is that amount of photosynthesis is immediately decreased in response to seasonally-decreased incident PAR intensity while rate of decline of total canopy chlorophyll is relatively slower during reproductive stages. Therefore, this would cause a significant bias in GPP estimations when estimating GPP directly from WDRVI without seasonality considerations. As shown in Figure $2 \mathrm{~B}$, the SW showed significant decrease starting in July. The monthly-average incoming SW intensity declined by $31 \%$ from July $\left(302 \mathrm{~W} / \mathrm{m}^{2}\right)$ to September $\left(209 \mathrm{~W} / \mathrm{m}^{2}\right)$ in 2003 . The decrease of SW is because the total hours of sunlight in the Northern Hemisphere gradually decrease after summer solstice around June 21 (DOY 172). The temporal features of the time-series SW, shown in Figure $2 \mathrm{~B}$, can be divided into two components. The first is a high frequency component (daily variation) caused by ever changing transmittance in atmosphere due to variation of amount of water vapor and cloud coverage. When the SW declined sharply (Figure $2 \mathrm{~B}$ 
Figure 5. The temporal behavior of GPP predictions in the growing season of 2007 derived from VR:SW*WDRVI and VR:WDRVI for (A) the irrigated crop, Site 1 , and (B) the rainfed crop, Site 3.
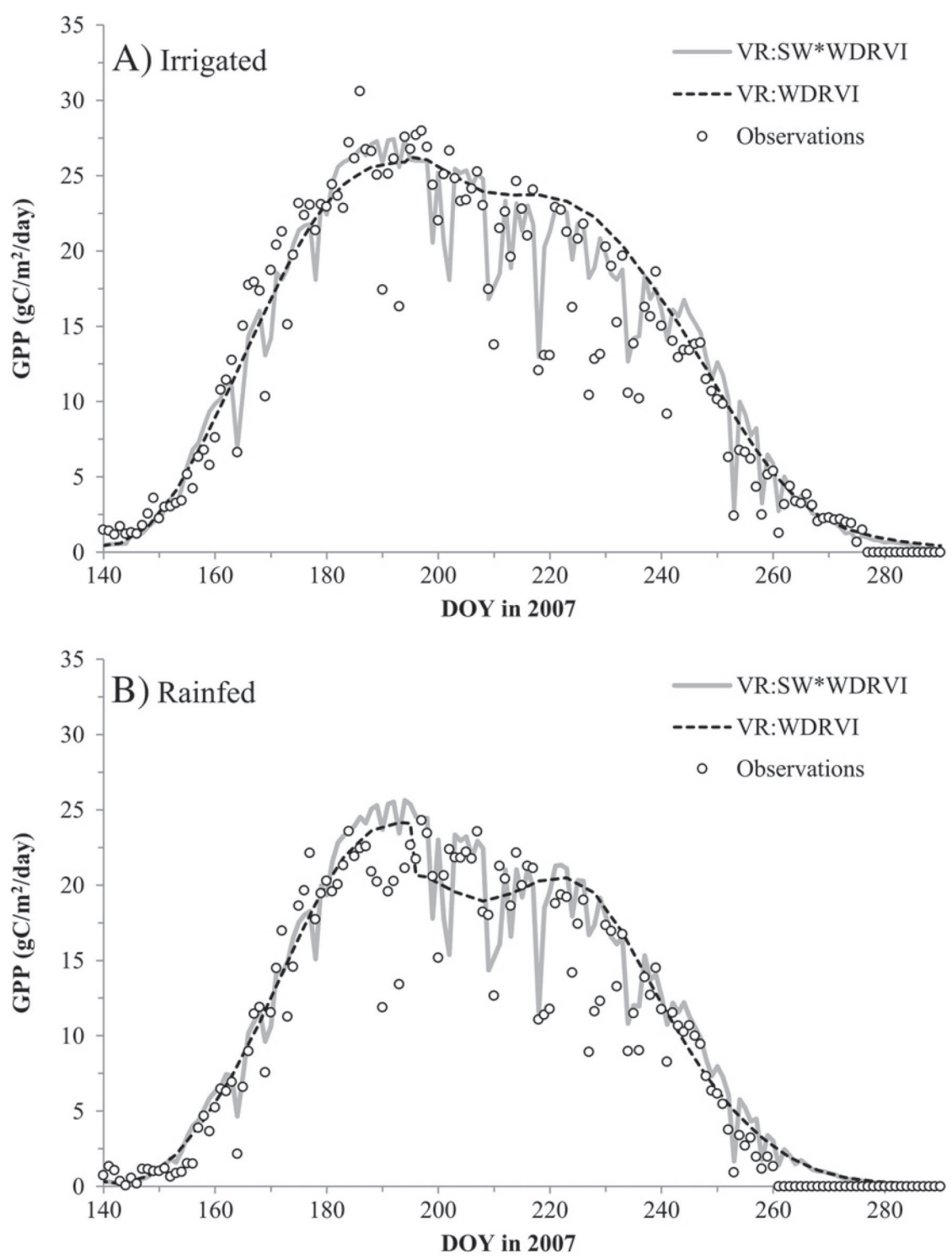

dash line), the observed GPP values also reduced sharply at the same time. The second temporal feature of SW is low frequency component mentioned above.

To take into account seasonality of incoming PAR, we considered estimating GPP based on the product of SW and WDRVI in the following forms:

$$
\begin{gathered}
S W * W D R V I=S W \times(W D R V I+S H I F T+0.5) \\
W D R V I+S H I F T+0.5 \geq 0
\end{gathered}
$$

where SW is daily-integrated short-wave radiation derived from the NLDAS-2 and WDRVI is daily smoothed WDRVI value. SHIFT is correction value to maintain variation range of a proxy variable of $\mathrm{Chl}_{\text {canopy }}$ more than or equal to o, which is corresponding to the term (WDRVI + SHIFT + 0.5) in Equation (4). Thus, minimum positive value is assigned to SHIFT to satisfy the conditional Equation (5) on a daily basis.

As a result, estimating GPP by product SSW * WDRVI (Equation (4)) allowed significant decrease in the gap between GPP and the product (Figure $2 \mathrm{~B}$ ). This is because the combination of specific frequency characteristics (short-term variation, long-term variation and seasonality) of time-series SW and WDRVI profiles well synthesizes temporal feature of GPP profile when the two variables are combined together in the product SW*WDRVI. Schubert et al. (2010b) also reported a similar rela- tionship between GPP and the product of $1 \mathrm{~km}$-resolution, 8-day composite EVI and $11-\mathrm{km}$ resolution photosynthetic photon flux density (PPFD) for two Swedish peatlands.

Temporal behavior of the $\mathrm{SW}^{*} \mathrm{WDRVI}$ during vegetative stage corresponds well with the temporal behavior of observed GPP (Figure $2 \mathrm{~B}$ ). However, a small gap between the SW*WDRVI and GPP still remained especially after DOY 240. In this period, top leaves clearly begin to senesce (Ciganda et al., 2008) and total canopy chlorophyll decreases. However, due to increase of senescing leaf transmittance, pathlength of light inside the canopy increases and, thus, the rate of WDRVI decrease is lower than the rate of decrease in total chlorophyll content (Merzlyak \& Gitelson, 1994).

\subsection{Model calibration and validation}

Scatter plot GPP vs. SW*WDRVI (Figure $3 \mathrm{~A}$ ) shows that the number of samples with GPP values below $20 \mathrm{gC} / \mathrm{m}^{2} /$ day, which is corresponding to specific periods during the early vegetative stage (DOY16o-180) and the later reproductive stage (DOY 250270), was less than the number of GPP values observed during the period from the late vegetative stage to the early reproductive stage (DOY 180-210). Thus, the uneven distribution of density of samples may also introduce bias in calibration that uses the approximate equation developed by a simple least-square re- 
Figure 6. Seasonal changes in the GPP predicted by model VR:SW*WDRVI and the flux tower-based GPP observations on the irrigated field (A to $\mathrm{G})$ and the rainfed field $(\mathrm{H})$.
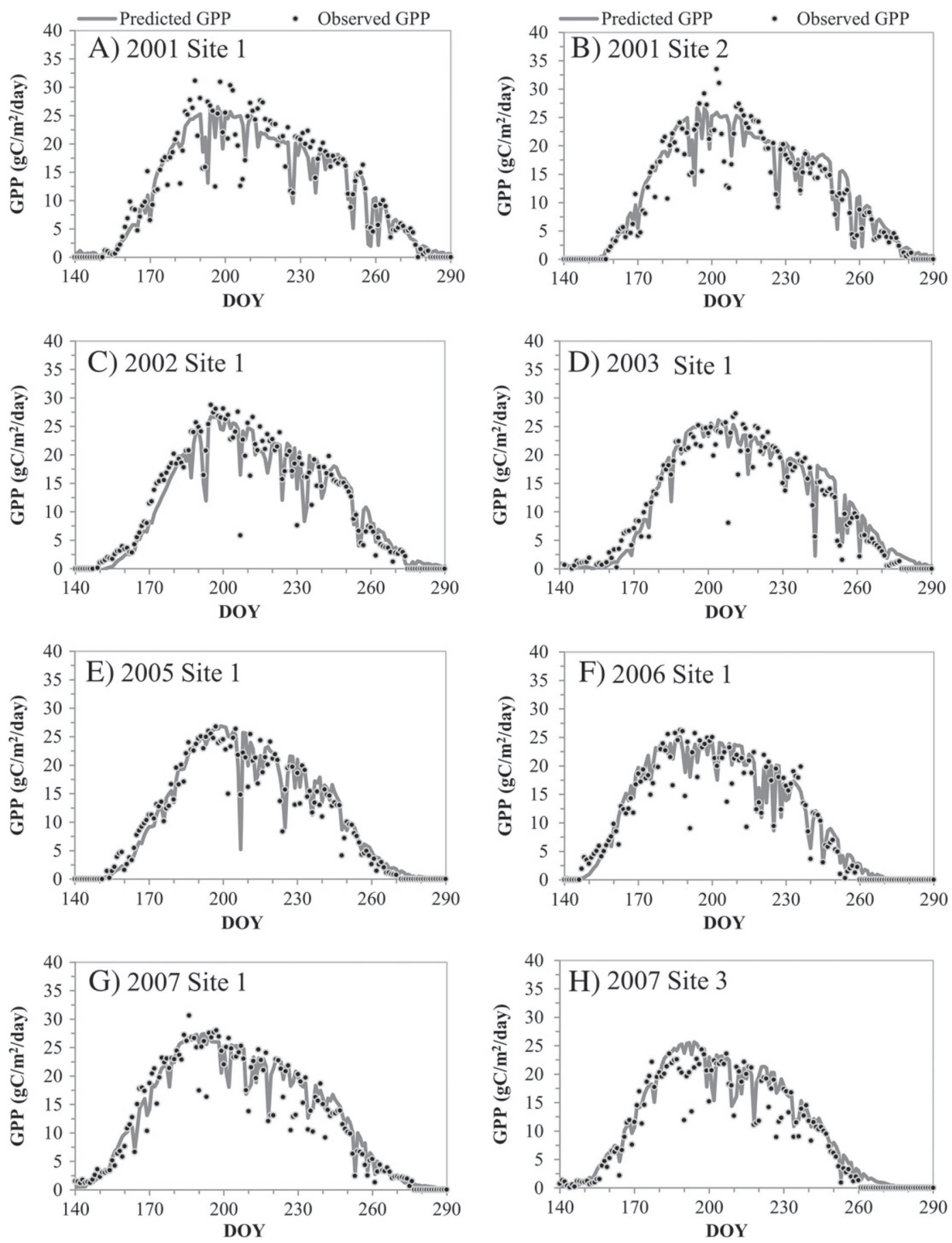

gression method. The scatter plots also included several outliers, which would affect the coefficients of the calibration equation. To avoid those influences, the relationship between GPP and $\mathrm{SW}^{*} \mathrm{WDRVI}$ was calibrated using the following procedure. First, the calibration samples were grouped into 12 classes at standard $30 \mathrm{SW}^{*} \mathrm{WDRVI}$ value intervals (e.g., classi: $\mathrm{o} \leq \mathrm{SW}{ }^{*} \mathrm{WDRVI}<30$, class2: $30 \leq \mathrm{SW}^{*} \mathrm{WDRVI}<60$, ..., class12: $\left.330<\mathrm{SW}^{*} \mathrm{WDRVI}\right)$. Second, the median values of GPP and SW*WDRVI were calculated for each class (circles in Figure 3). Finally, a third-order polynomial best-fit function (passing through the origin) was derived from these median values using the least-squares method. We established three calibration relationships between the observed GPP and the product SW*WDRVI (Figure 3): (i) whole season, denoted as W (Figure $3 \mathrm{~A}$ ); (ii) vegetative stage from DOY 160 to the R1 stage, denotes as V (Figure $3 \mathrm{~B}$ ); and (iii) reproductive stage from the $\mathrm{R}_{1}$ stage to DOY 270 , denoted as $\mathrm{R}$ (Figure $3 \mathrm{C}$ ). The coefficients of each third-order polynomial regression model $\left(y=a x^{3}+b^{2}+c x\right)$ for estimating daily GPP are shown in Table 1.

All relationships were non-linear with decrease in slope at higher SW*WDRVI values (> 250) regardless of target calibration period (Figure 3). This non-linear behavior was also found in the relationship between midday GPP and the product of PAR and total canopy chlorophyll content for maize and soybeans in an earlier study by Gitelson et al. (2006). According to the calibration results (Table 1), V:SW*WDRVI had a lower coefficient of variation $(\mathrm{CV}=17.3 \%)$ and higher mean normalized bias $(\mathrm{MNB}=5.1 \%)$ than $\mathrm{W}: \mathrm{SW}^{*} \mathrm{WDRVI}(\mathrm{CV}=19.5 \%, \mathrm{MNB}=4.0 \%)$. Although 
Figure 7. Comparison in accumulated GPP profiles from DOY 160-270 between the model (VR:SW*WDRVI)-derived predictions/ estimations and the ground-based observations on the irrigated field (Site 1, A to D) and the rainfed field (Site 3, E to H).
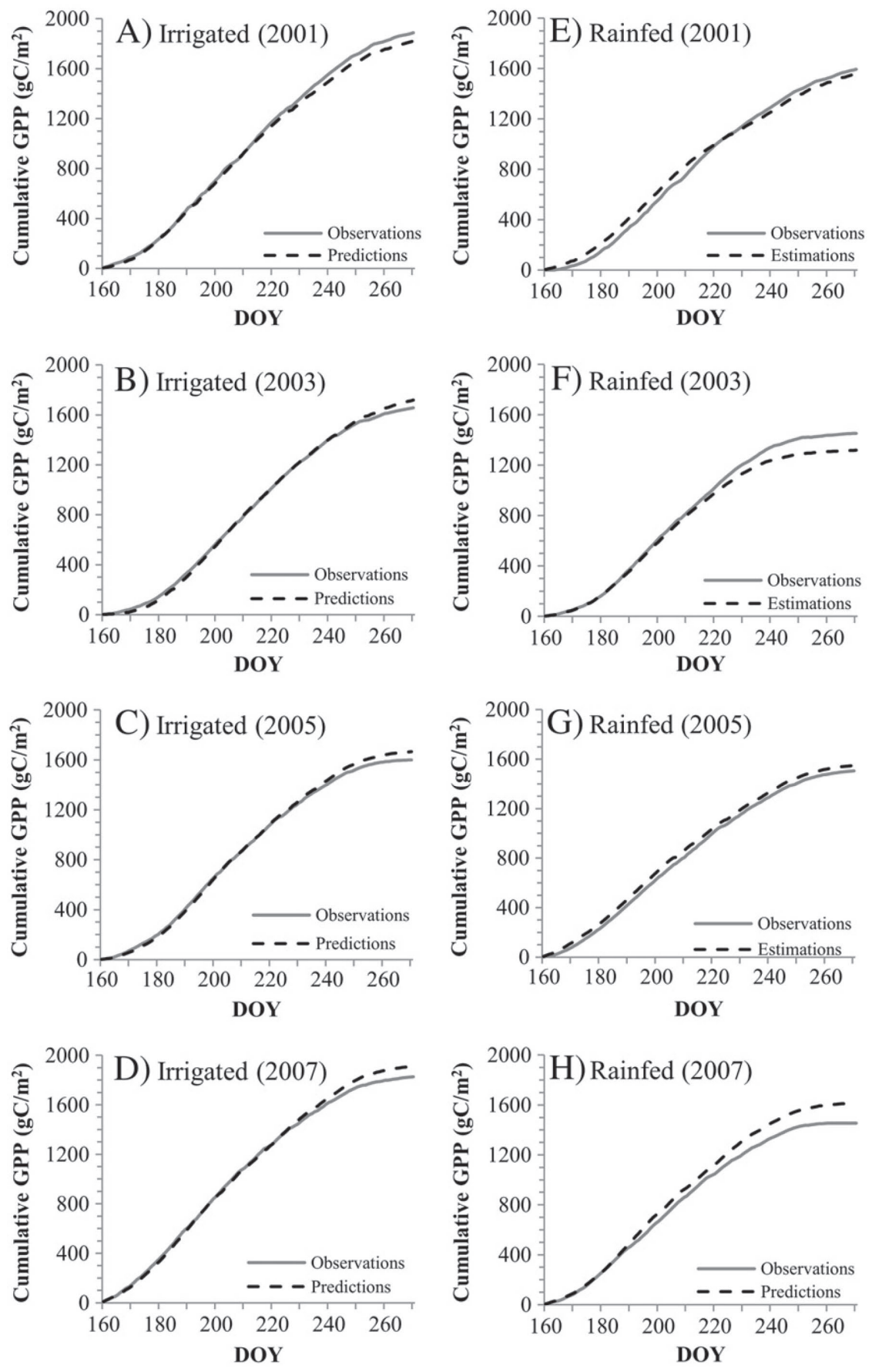

there was no difference in the coefficient of variation between $\mathrm{R}: S W^{*} \mathrm{WDRVI}(\mathrm{CV}=19.5 \%)$ and $\mathrm{W}: \mathrm{SW}^{*} \mathrm{WDRVI}$, the mean normalized bias of R:SW*WDRVI $(\mathrm{MNB}=2.3 \%)$ was significantly lower than that of W:SW*WDRVI. The use of the segmented calibration using the phenology information (using the date of R1 stage to divide the growing season) benefited the accuracy of GPP estimation in vegetative stage more than in the reproductive stage.

The established relationships GPP vs. SW*WDRVI (Table 1) were applied to the validation datasets without adjustment of the coefficients. Then, the predicted GPP values were compared with the observed GPP values (Figure 4). The difference in prediction accuracy among the approximate models was similar to the estimation accuracy of each GPP model (Table 1). The prediction accuracy of the V:SW*WDRVI $(C V=17.8 \%, M N B=2.3 \%)$ was better than that of the W:SW ${ }^{*}$ WDRVI $(C V=21.6 \%$, $\mathrm{MNB}=6.1 \%)$. However, the CV of R:SW*WDRVI (21.0\%) was a little smaller than that of $\mathrm{W}: S W^{*} \mathrm{WDRVI}(\mathrm{CV}=21.6 \%)$ and the MNB of R:SW*WDRVI (7.7\%) was higher than that of $\mathrm{W}: \mathrm{SW}^{*} \mathrm{WDRVI}(\mathrm{MNB}=6.1 \%)$.

\subsection{GPP estimation via WDRVI and $S W^{*} W D R V I$}

While WDRVI does not follow high frequency variations in GPP, the WDRVI alone does trace the seasonal GPP profile quite well during the vegetative stage. Applied phenology-segmented calibration eliminated the difference in seasonality between the temporal GPP profile and the smoothed WDRVI profile and improved significantly prediction accuracy (compare Figure 5 and Figure $2 \mathrm{~A}$ ). The prediction accuracy of $\mathrm{V}:$ WDRVI $\left(\mathrm{CV}=19.6 \%\right.$, RMSE $=3.29 \mathrm{gC} / \mathrm{m}^{2} /$ day, $\mathrm{MNB}=4.9 \%$, $\left.\mathrm{R}^{2}=0.82\right)$ and R:WDRVI $\left(\mathrm{CV}=28.1 \%\right.$, RMSE $=4.00 \mathrm{gC} / \mathrm{m}^{2} /$ day, $\mathrm{MNB}=21.8 \%, \mathrm{R}^{2}=0.78$ ) was better than that of $\mathrm{W}$ :WDRVI 
Figure 8. Temporal change in error of cumulative GPP predictions/estimations in the irrigated field (Site 1 ) and the rainfed field (Site 3) in the odd years (A to D).
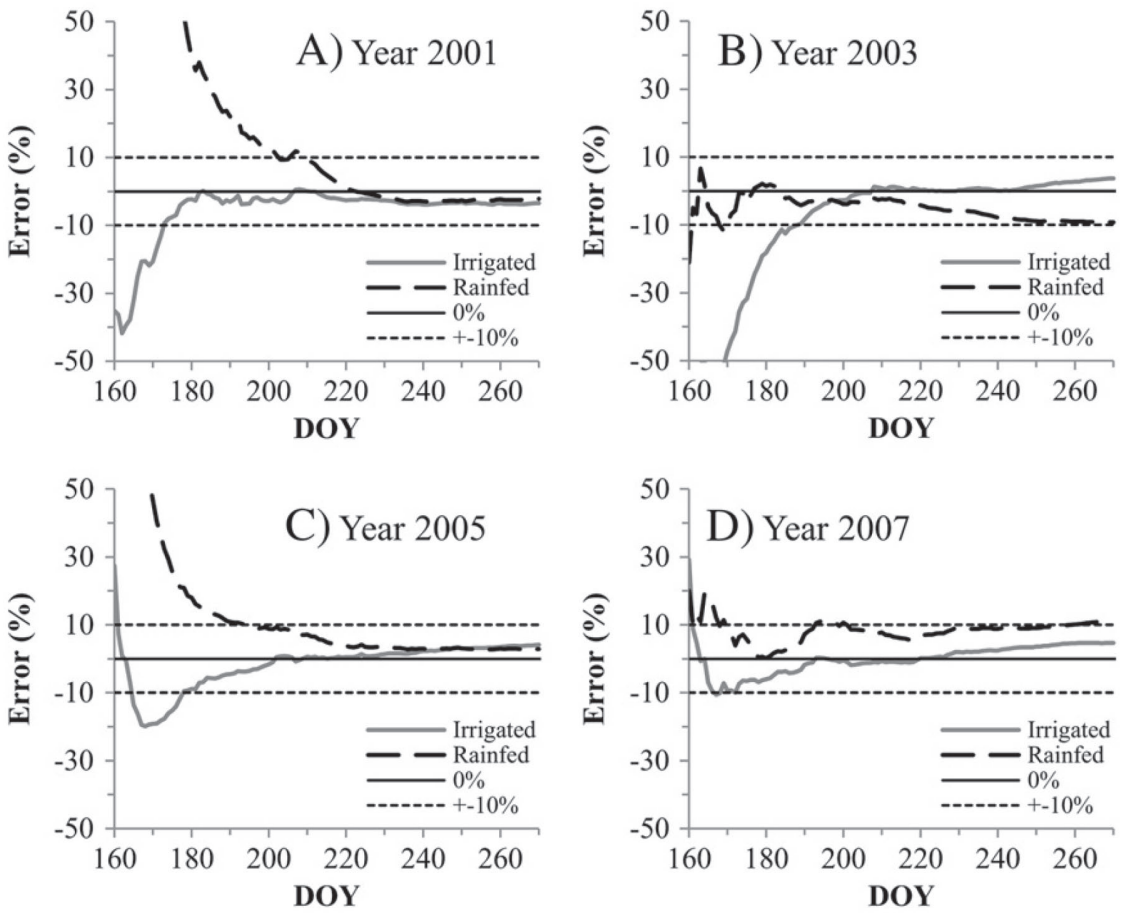

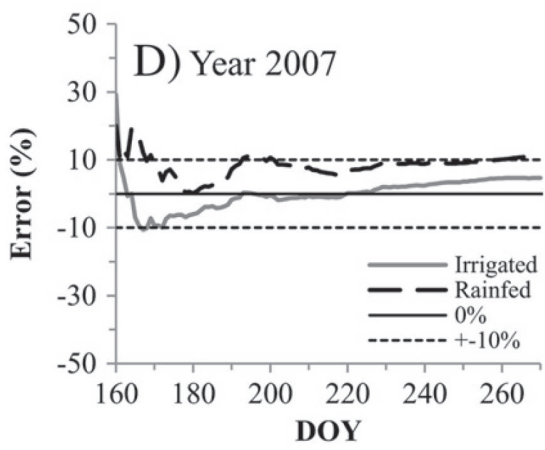

$\left(\mathrm{CV}=30.5 \%, \mathrm{RMSE}=4.62 \mathrm{gC} / \mathrm{m}^{2} /\right.$ day, $\left.\mathrm{MNB}=15.9 \%, \mathrm{R}^{2}=0.66\right)$. Thus, the GPP model based only on WDRVI could quantify GPP values of maize with reasonable accuracy as long as it was calibrated separately for the two maize phenological stages. This approach could be used for estimating GPP when moderate resolution daily product of incident light intensity is not available.

Using two established relationships, one for vegetative stage (V:WDRVI and V:SW*WDRVI) and another for reproductive stage (R:WDRVI and R:SW*WDRVI), we calculated WDRVI and SW*WDRVI profiles for whole year and compared them with GPP profile for irrigated and rainfed maize in 2007 (Figure 5). We referred to them as VR:WDRVI and VR:SW*WDRVI. The product SW*WDRVI predicted GPP more accurately than WDRVI alone. The prediction accuracy of VR:SW*WDRVI was high $\left(\mathrm{CV}=19.7 \%, \mathrm{RMSE}=2.99 \mathrm{gC} / \mathrm{m}^{2}, \mathrm{MNB}=5.7 \%, \mathrm{R}^{2}=0.86\right)$ and better than that for whole season W:SW ${ }^{*}$ WDRVI $(\mathrm{CV}=21.6 \%$, RMSE $\left.=3.28 \mathrm{gC} / \mathrm{m}^{2}, \mathrm{MNB}=6.1 \%, \mathrm{R}^{2}=0.83\right)$. Importantly, both VR:SW*WDRVI and W:SW*WDRVI were more accurate in GPP prediction than VR:WDRVI $\left(\mathrm{CV}=24.8 \%\right.$, RMSE $=3.76 \mathrm{gC} / \mathrm{m}^{2}$, $\mathrm{MNB}=15.6 \%, \mathrm{R}^{2}=0.79$ ).

Detailed daily temporal GPP profiles were reconstructed using the VR:SW*WDRVI model (Figure 6). The temporal features of the predicted GPP profiles matched well those of observed GPP. In particular, a high level of temporal agreement was observed during the short vegetative and longer reproductive periods when both profiles exhibited similar rapid increasing trend-like sigmoid pattern and a less pronounced decreasing trend-like inverse-sigmoid pattern, respectively. However, the VR:SW*WDRVI did not detect all of short-term GPP reductions because the reanalysis SW data tended to overestimate the actual incident PAR as shown in Figure $1 B$. The uncertainties in the daily meteorological reanalysis of SW and in relationship between PAR and SW are partially responsible for the errors in GPP estimates derived from the simple GPP model (Zhao et al., 2006; Pinker et al., 2010).

\subsection{Estimation of cumulative GPP}

Figure 7 shows the cumulative flux tower-based observations of GPP and the VR:SW*WDRVI-derived estimations for entire growing season (DOY 160-270) of odd years (when maize were grown on all three sites) in the study period. The profiles of cumulative GPP estimates were well fitted with those of the flux tower observations during both the vegetative and early reproductive stages. During both stages, the GPP model characterized the specific features of the flux tower-based cumulative GPP profiles and captured increase rate of GPP of the irrigated fields compared to the rainfed field. The temporal profile of $\mathrm{cu}^{-}$ mulative GPP estimation error tended to be stable especially after vegetative stage (Figure 8). In 2005 and 2007, rainfed fields had larger margin of error during the reproductive stage than those of irrigated fields. The considerable GPP reductions especially during the reproductive stage were not detected accurately by VR:SW*WDRVI (Figure 6) because the daily variation of incident PAR intensity tends to be overestimated (Figure $1 \mathrm{~B}$ ) when using SW of reanalysis data as a proxy variable of PAR in GPP model (Zhao et al., 2006; Pinker et al., 2010). Although the VR:SW*WDRVI could not estimate subtle changes in GPP precisely, it did capture the primary temporal shape characteristics of the seasonal GPP variations. Importantly, the VR:SW*WDRVI estimated the total growing-season GPP value with very high accuracy (Figure 9, RMSE $=83 \mathrm{gC} / \mathrm{m}^{2}, \mathrm{CV}=5.0 \%, \mathrm{MNB}=1.9 \%$ ).

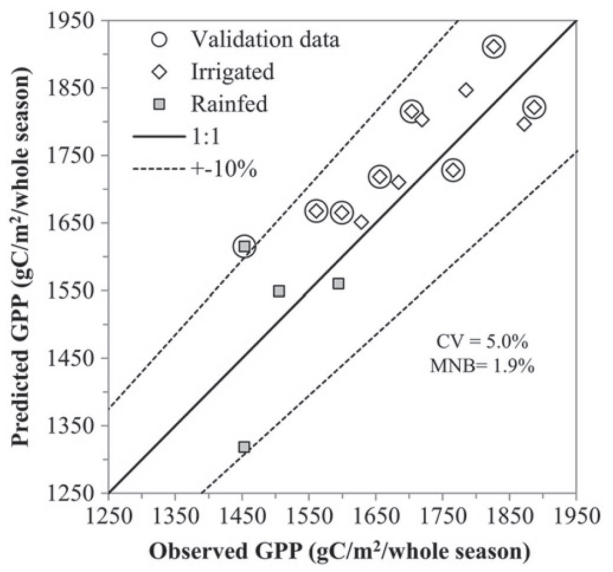

Figure 9. Comparison in growing-season total GPP value between the model (VR:SW*WDRVI)-derived estimations and the ground-based observations. 


\section{Conclusions}

In this study, we developed and tested a model for predicting daily and seasonal GPP variation of maize based only on remote sensing and reanalysis data. The proposed GPP model was based on the product of time-series MODIS $250 \mathrm{~m}$ WDRVI data and the shortwave radiation (SW) from NLADS-2. Time-series comparisons found a remarkable difference in the seasonal response between smoothed WDRVI profile and the observed temporal GPP profile. Although it was possible to predict the seasonality of GPP from WDRVI alone with a phenology-segmented calibration model, this WDRVI-only approach resulted in the lower predictive accuracy than the approach that combined both WDRVI and SW data (SW*WDRVI). The results clearly showed that the temporal response of the smoothed WDRVI profile was a function of seasonal changes in potential photosynthetic capacity, while the daily SW profile changes were a function of both seasonal changes in sunshine duration (i.e., day length) and short-term variability (caused by daily weather conditions) in incident PAR intensity. The model VR:SW*WDRVI that consists of two separately calibrated relationships GPP vs. SW*WDRVI for vegetative and reproductive stages minimized the difference in seasonality between SW*WDRVI and GPP and resulted in a higher predicted accuracy (CV $=19.7 \%$, RMSE $=2.99 \mathrm{gC} / \mathrm{m}^{2} /$ day, $\left.\mathrm{MNB}=5.7 \%, \mathrm{R}^{2}=0.86\right)$ than that of calibrated for the whole growing season, W:SW*WDRVI $\left(\mathrm{CV}=21.6 \%, \mathrm{RMSE}=3.28 \mathrm{gC} / \mathrm{m}^{2} /\right.$ day, $\left.\mathrm{MNB}=6.1 \%, \mathrm{R}^{2}=0.83\right)$. While the model VR:SW*WDRVI tended to slightly overestimate the total GPP value because of the uncertainties of relationship between incident PAR and SW, the accuracy of the seasonal total estimated GPP is very high: $\mathrm{CV}=5.0 \%$ and mean normalized bias is below $1.9 \%$. In addition, the cumulative GPP profiles, derived by VR:SW*WDRVI, clearly discriminated the GPP differences between irrigated and rainfed maize fields, which was consistent with the ground-based GPP observations.

The developed simple GPP model based on the product of MODIS $250 \mathrm{~m}$ WDRVI data and SW from reanalysis data can accurately predict the daily temporal GPP profile of maize growth. This study showed that the unique approach considering the crop developmental stage for calibrating GPP model (the phenology-segmented calibration model) improved the estimation accuracy. We considered this model as an applicable approach to evaluate regional-scale temporal GPP patterns of maize because the input variables (MODIS and reanalysis data) are readily available for large geographic areas and for an extended time period (i.e., more than 10 years). Future research is planned that will apply this approach to both of maize and soybean at a larger regional-scale across the U.S. Corn Belt in order to investigate the spatio-temporal relationship between meteorological variability and carbon assimilation through crop growth.

Acknowledgments - We gratefully acknowledge the use of facilities and equipment provided by the National Drought Mitigation Center, School of Natural Resources, University of Nebraska-Lincoln. $\mathrm{CO}_{2}$ flux and other measurements were supported by the Office of Science (BER), U.S. Department of Energy Grant No. DE-FGo2-03ER63639 and NASA NACP grant no. NNXo8AI75G. The remote sensing-based analyses were financially supported by the Japanese Society for the Promotion of Science; JSPS Postdoctoral Fellowships for Research Abroad. We are grateful to Mr. Anthony Nguy-Robertson and Ms. Yi Peng for their valuable assistance in calculating GPP data.

\section{References}

Baret, F., Houles, V., \& Gu Rif, M. (2007). Quantification of plant stress using remote sensing observations and crop models: The case of nitrogen management. Journal of Experimental Botany, 58, 869-88o.
Chen, B., Ge, Q., Fu, D., Liu, G., Yu, G., Sun, X., et al. (2009). Upscaling of gross ecosystem production to the landscape scale using multitemporal Landsat images, eddy covariance measurements and a footprint model. Biogeosciences Discussions, 6, 11317-11345.

Ciganda, V., Gitelson, A. A., \& Schepers, J. (2008). Vertical profile and temporal variation of chlorophyll in maize canopy: Quantitative "crop vigor" indicator by means of reflectance-based techniques. Agronomy Journal, 100, 1409-1417. doi:10.2134/agronj2007.0322.

Fang, H. (2009). Read me document for North America Land Data Assimilation System Phase 2 (NLDAS-2) Products. Goddard Earth Sciences Data and Information Services Center; available at http:// hydro1.sci.gsfc.nasa.gov/data/s4pa/NLDAS/README.NLDAS2.pdf

Gamon, J. A., Penuelas, J., \& Field, C. B. (1992). A narrow-waveband spectral index that tracks diurnal changes in photosynthetic efficiency. Remote Sensing of Environment, 41, 35-44.

Gitelson, A. A. (2004). Wide dynamic range vegetation index for remote quantification of biophysical characteristics of vegetation. Journal of Plant Physiology, 161, 165-173.

Gitelson, A. A., Verma, S. B., Vina, A., Rundquist, D. C., Keydan, G., Leavitt, B., et al. (2003). Novel technique for remote estimation of $\mathrm{CO}_{2}$ flux in maize. Geophysical Research Letters, 30, 1486. doi:10.1029/2002GLo16543.

Gitelson, A. A., Vina, A., Masek, J. G., Verma, S. B., \& Suyker, A. E. (2008). Synoptic monitoring of gross primary productivity of maize using Landsat data. IEEE Geoscience and Remote Sensing Letters, 5, 133-137.

Gitelson, A. A., Vina, A., Verma, S. B., Rundquist, D. C., Arkebauer, T. J., Keydan, G., et al. (2006). Relationship between gross primary production and chlorophyll content in crops: Implications for the synoptic monitoring of vegetation productivity. Journal of Geophysical Research-Atmospheres, 111, Do8S11. doi:10.1029/2005JDoo6017.

Gitelson, A. A., Wardlow, B. D., Keydan, G. P., \& Leavitt, B. (2007). An evaluation of MODIS 250-m data for green LAI estimation in crops. Geophysical Research Letters, 34, L20403. doi:10.1029/2007GLo31620.

Harazono, Y., Chikamoto, K., Kikkawa, S., Iwata, T., Nishida, N., Ueyama, M., et al. (2009). Applications of MODIS-visible bands index, greenery ratio to estimate $\mathrm{CO}_{2}$ budget of a rice paddy in Japan. Journal of Agricultural Meteorology, 65, 365-374.

Harris, A., \& Dash, J. (2010). The potential of the MERIS Terrestrial Chlorophyll Index for carbon flux estimation. Remote Sensing of Environment, 114, 1856-1862.

Houborg, R., Anderson, M. C., Daughtry, C. S. T., Kustas, W. P., \& Rodell, M. (2011). Using leaf chlorophyll to parametrize light-use-efficiency within a thermal-based carbon, water and energy exchange model. Remote Sensing of Environment, 115, 1694-1705.

Huete, A., Didan, K., Miura, T., Rodriguez, E. P., Gao, X., \& Ferreira, L. G. (2002). Overview of the radiometric and biophysical performance of the MODIS vegetation indices. Remote Sensing of Environment, 83, 195-213.

Inoue, Y., Penuelas, J., Miyata, A., \& Mano, M. (2008). Normalized difference spectral indices for estimating photosynthetic efficiency and capacity at a canopy scale derived from hyperspectral and $\mathrm{CO}_{2}$ flux measurements in rice. Remote Sensing of Environment, 112, 156-172.

Jahan, N., \& Gan, T. Y. (2009). Modeling gross primary production of deciduous forest using remotely sensed radiation and ecosystem variables. Journal of Geophysical Research-Biogeosciences, 114.

Kitamoto, T., Ueyama, M., Harazono, Y., Iwata, T., \& Yamamoto, S. (2007). Applications of NOAA/AVHRR and observed fluxes to estimate 3 regional carbon fluxes over black spruce forests in Alaska. Journal of Agricultural Meteorology, 63, 171-183.

Lokupitiya, E., Denning, S., Paustian, K., Baker, I., Schaefer, K., Verma, S., et al. (2009). Incorporation of crop phenology in Simple Biosphere Model (SiBcrop) to improve land-atmosphere carbon exchanges from croplands. Biogeosciences, 6, 969-986.

Merzlyak, M. N., \& Gitelson, A. (1994). Why and what for the leaves are yellow in autumn? On the interpretation of optical spectra of senescing leaves (Acer platanoides L.). Journal of Plant Physiology, $145,315-320$. 
Monteith, J. L. (1972). Solar radiation and productivity in tropical ecosystems. Journal of Applied Ecology, 9, 747-766.

Nagai, S., Saigusa, N., Muraoka, H., \& Nasahara, K. N. (2010). What makes the satellite-based EVI-GPP relationship unclear in a deciduous broad-leaved forest? Ecological Research, 25, 359-365.

Nakaji, T., Ide, R., Oguma, H., Saigusa, N., \& Fujinuma, Y. (2007). Utility of spectral vegetation index for estimation of gross $\mathrm{CO}_{2}$ flux under varied sky conditions. Remote Sensing of Environment, 109, 274-284.

Peng, Y., Gitelson, A. A., Keydan, G., Rundquist, D. C., \& Moses, W. (2011). Remote estimation of gross primary production in maize and support for a new paradigm based on total crop chlorophyll content. Remote Sensing of Environment, 115, 978-989.

Pinker, R. T., Zhao, M. S., Wang, H. M., \& Wood, E. F. (2010). Impact of satellite based PAR on estimates of terrestrial net primary productivity. International Journal of Remote Sensing, 31, 5221-5237.

Rouse, J. (1974). Monitoring vegetation systems in the Great Plains with ERTS. (In). Ruimy, A., Saugier, B., \& Dedieu, G. (1994). Methodology for the estimation of terrestrial net primary production from remotely sensed data. Journal of Geophysical Research- Atmospheres, 99, 5263-5283.

Running, S. W., Nemani, R., Glassy, J. M., \& Thornton, P. E. (1999). MODIS daily photosynthesis (PSN) and annual net primary production (NPP) product (MOD17) Algorithm Theoretical Basis Document. University of Montana, SCF At-Launch Algorithm ATBD Documents, available online at http://www.ntsg.umt.edu/modis/ ATBD/ATBD_MOD17_v21.pdf

Running, S. W., Nemani, R. R., Heinsch, F. A., Zhao, M. S., Reeves, M., \& Hashimoto, H. (2004). A continuous satellite-derived measure of global terrestrial primary production. Bioscience, 54, 547-560.

Running, S., Thornton, P., Nemani, R., \& Glassy, J. (2000). Global terrestrial gross and net primary productivity from the Earth Observing System. Methods in Ecosystem Science, 44-57.

Sakamoto, T., Wardlow, B. D., \& Gitelson, A. A. (2011). Detecting spatio-temporal changes of corn developmental stages in the U.S. Corn Belt using MODIS WDRVI data. IEEE Transactions On Geoscience and Remote Sensing, 49, 1926-1936.

Sakamoto, T., Wardlow, B. D., Gitelson, A. A., Verma, S. B., Suyker, A. E., \& Arkebauer, T. J. (2010). A Two-Step Filtering approach for detecting maze and soybean phenology with time-series MODIS data. Remote Sensing of Environment, 114, 2146-2159.

Sakamoto, T., Yokozawa, M., Toritani, H., Shibayama, M., Ishitsuka, N., \& Ohno, H. (2005). A crop phenology detection method using time-series MODIS data. Remote Sensing of Environment, 96, 336-374.

Schubert, P., Eklundh, L., Lund, M., \& Nilsson, M. (2010). Estimating northern peatland $\mathrm{CO}_{2}$ exchange from MODIS time series data. Remote Sensing of Environment, 114, 1178-1189.

Schubert, P., Lund, M., Ström, L., \& Eklundh, L. (2010). Impact of nutrients on peatland GPP estimations using MODIS time series data. Remote Sensing of Environment, 114, 2137-2145.

Sims, D. A., Rahman, A. F., Cordova, V. D., El-Masri, B. Z., Baldocchi, D. D., Flanagan, L. B., et al. (2006). On the use of MODIS EVI to assess gross primary productivity of North American ecosystems. Journal of Geophysical Research-Biogeosciences, 111.

Sjostrom, M., Ardo, J., Eklundh, L., El-Tahir, B. A., El-Khidir, H. A. M., Hellstrom, M., et al. (2009). Evaluation of satellite based indices for gross primary production estimates in a sparse savanna in the Sudan. Biogeosciences, 6, 129-138.

Suyker, A. E., Verma, S. B., Burba, G. G., \& Arkebauer, T. J. (2005). Gross primary production and ecosystem respiration of irrigated maize and irrigated soybean during a growing season. Agricultural and Forest Meteorology, 131, 180-190.

Suyker, A. E., Verma, S. B., Burba, G. G., Arkebauer, T. J., Walters, D. T., \& Hubbard, K. G. (2004). Growing season carbon dioxide exchange in irrigated and rainfed maize. Agricultural and Forest Meteorology, 124, 1-13.
Thenkabail, P. S., Schull, M., \& Turral, H. (2005). Ganges and Indus river basin land use/land cover (LULC) and irrigated area mapping using continuous streams of MODIS data. Remote Sensing of Environment, 95, 317-341.

Tucker, C. J. (1979). Red and photographic infrared linear combinations for monitoring vegetation. Remote Sensing of Environment, $8,127-150$.

Turner, D. P., Ritts, W. D., Zhao, M. S., Kurc, S. A., Dunn, A. L., Wofsy, S. C., et al. (2006). Assessing interannual variation in MODISbased estimates of gross primary production. IEEE Transactions on Geoscience and Remote Sensing, 44, 1899-1907.

Verma, S. B., Dobermann, A., Cassman, K. G., Walters, D. T., Knops, J. M., Arkebauer, T. J., et al. (2005). Annual carbon dioxide exchange in irrigated and rainfed maize-based agroecosystems. Agricultural and Forest Meteorology, 131, 77-96.

Vermote, E. F., El Saleous, N. Z., \& Justice, C.O. (2002).Atmospheric correction of MODIS data in the visible to middle infrared: First results. Remote Sensing of Environment, 83, 97-111.

Vina, A., \& Gitelson, A. A. (2005). New developments in the remote estimation of the fraction of absorbed photosynthetically active radiation in crops. Geophysical Research Letters, 32.

Wu, C. Y., Niu, Z., Tang, Q., Huang, W. J., Rivard, B., \& Feng, J. L. (2009). Remote estimation of gross primary production in wheat using chlorophyll-related vegetation indices. Agricultural and Forest Meteorology, 149, 1015-1021.

Xiao, X., Boles, S., Frolking, S., Li, C., Babu, J. Y., Salas, W., et al. (2006). Mapping paddy rice agriculture in South and Southeast Asia using multi-temporal MODIS images. Remote Sensing of Environment, 100, 95-113.

Xiao, X., Boles, S., Frolking, S., Salas, W., Moore, B., Li, C., et al. (2002). Observation of flooding and rice transplanting of paddy rice fields at the site to landscape scales in China using VEGETATION sensor data. International Journal of Remote Sensing, 23, 3009-3022.

Xiao, X. M., Hollinger, D., Aber, J., Goltz, M., Davidson, E. A., Zhang, Q. Y., et al. (2004). Satellite-based modeling of gross primary production in an evergreen needleleaf forest. Remote Sensing of Environment, 89, 519-534.

Xiao, X. M., Zhang, Q. Y., Braswell, B., Urbanski, S., Boles, S., Wofsy, S., et al. (2004). Modeling gross primary production of temperate deciduous broadleaf forest using satellite images and climate data. Remote Sensing of Environment, 91, 256-270.

Xiao, X. M., Zhang, Q. Y., Hollinger, D., Aber, J., \& Moore, B. (2005). Modeling gross primary production of an evergreen needleleaf forest using MODIS and climate data. Ecological Applications, 15, 954-969.

Xiao, J. F., Zhuang, Q. L., Law, B. E., Chen, J. Q., Baldocchi, D. D., Cook, D. R., et al. (2010). A continuous measure of gross primary production for the conterminous United States derived from MODIS and AmeriFlux data. Remote Sensing of Environment, 114, 576-591.

Yan, H. M., Fu, Y. L., Xiao, X. M., Huang, H. Q., He, H. L., \& Ediger, L. (2009). Modeling gross primary productivity for winter wheatmaize double cropping system using MODIS time series and $\mathrm{CO}_{2}$ eddy flux tower data. Agriculture, Ecosystems and Environment, 129, 391-400.

Yuan, W. P., Liu, S. G., Yu, G. R., Bonnefond, J. M., Chen, J. Q., Davis, K., et al. (2010). Global estimates of evapotranspiration and gross primary production based on MODIS and global meteorology data. Remote Sensing of Environment, 114, 1416-1431.

Zhao, M. S., Heinsch, F. A., Nemani, R. R., \& Running, S. W. (2005). Improvements of the MODIS terrestrial gross and net primary production global data set. Remote Sensing of Environment, 95, 164-176.

Zhao, M., Running, S. W., \& Nemani, R. R. (2006). Sensitivity of Moderate Resolution Imaging Spectroradiometer (MODIS) terrestrial primary production to the accuracy of meteorological reanalyses. Journal of Geophysical Research-Biogeosciences, 111. 